Indonesian Journal of Physics

Vol 22 No. 3, July 2011

\title{
Calculation Procedure for Dynamic Condition of Ion Composition in Cell Walls Altered by Proton Fluxes
}

\author{
Idam Arif \\ Nuclear Physics and Biophysics Research Division \\ Faculty of Mathematics and Natural Sciences, Institut Teknologi Bandung \\ e-mail: idam@fi.itb.ac.id
}

Received 4 February 2011, Revised 11 March 2011, Accepted 27 May 2011

\begin{abstract}
The calculation procedure has been developed to determine the dynamic condition of the ion composition in cell walls during proton extrusion, known as the Weak Acid Donnan Manning (WADM) model for fluxes. In this model, the walls of plant cells are considered as a system containing weak acid polymers where the interaction of ions obeys the Manning condensation theory and the Donnan theory. When protons are transported across the walls during proton fluxes, the transported proton will interact with the wall ions and alter the ion composition. This depends on the wall parameters such as the concentration of ionisable sites, the $\mathrm{pK}$ of the wall weak acid, and the wall linear charge density parameter. When the linear charge density parameter is still higher than the reciprocal of the highest valence of the involve cations, the transported protons during proton fluxes will decrease the wall $p H$, alter the ion composition in the wall Donnan free space and water free space, and release the condensed cations. Therefore some of the proton fluxes are represented by the flux of the condensed cations outside the walls. However when the linear charge density parameter is less than the reciprocal of the highest valence of the involve cations, there is no condensed cations in the walls so that the transported protons only alter the ion composition in the wall Donnan free space and water free space.
\end{abstract}

Keywords: Cell walls; Weak acids; Manning condensation; Donnan theory; Proton fluxes.

\section{Introduction}

The walls of plant cells modify the ionic composition at the surface of the plasmalemma from its surrounding medium. The walls that contain weak acid polymers have fixed negative charges. Therefore cations from the surrounding medium tend to gather in the walls ${ }^{1)}$. Sentenac and Grignon had proposed a model for predicting the ionic equilibrium concentration in cell walls of Horse been roots ${ }^{2}$. Furthermore, to study the ion behavior in plant cell walls, the weak acid Donnan-Manning (WADM) model that employs the Manning condensation theory ${ }^{3)}$ and the Donnan theory has been proposed by Richter and Dainty for Sphagnum russowii cell walls $^{4-7)}$. This WADM model has been used by Ryan et al. to explain rapid calcium exchange for protons and potassium in Chara cell walls ${ }^{8)}$. In the study, the model was used to calculate the wall parameters for the treatment condition of the external medium used in their experiment. In this case, the calculation was carried out by assuming that the equilibrium condition between the walls and the external medium has been established. Therefore the calculation process could be done almost straightly forward.

In the case that the equilibrium condition between the walls and the external medium has not been established such as in the case that the wall $\mathrm{pH}$ is continuously altered by proton efflux, the calculation needs further investigation. In such dynamic situation, the ion composition in the walls is also continuously altered when proton are transported across the walls during proton fluxes. This is due to the interaction of the transported proton ions with the wall weak acids and other ions in the surrounding medium. In plant cells, proton ions are transported across the palsmalemma to or from the cell walls. Therefore it is useful to describe the effect of transported proton ions during proton fluxes on the ion composition in the cells walls and the fluxes of ions outside the walls using the WADM model. This calculation model is introduced as the WADM model for fluxes. Arif and Newman have described this model very brief in relation to explain the observed calcium efflux due to proton extrusion from oat coleoptile cells during fusicoccin action ${ }^{9)}$. This calcium-proton exchange during proton extrusion from plant cell walls is important and must be considered when the ion fluxes are observed outside plant cell walls such as in the measurement of fluxes using ion selective microelectrodes. Due to the importance of this issue, the calculation procedure of the WADM model for fluxes will be presented in more details in this study. This study describes every time step of changes of wall parameters as the results of proton fluxes through plant cell walls. This model will also provide the estimated fluxes of related ions outside the cell walls due to the proton fluxes as function of time.

\section{Calculation Procedure}

\subsection{Initial conditions}

To start with the WADM model for fluxes, we consider plant cells bathed with a medium containing $\left[\mathrm{K}_{\mathrm{o}}\right]$ mole $\mathrm{m}^{-3}$ of potassium, $\left[\mathrm{Ca}_{\mathrm{o}}\right]$ mole $\mathrm{m}^{-3}$ of calcium, $\left[\mathrm{Na}_{\mathrm{o}}\right]$ mole $\mathrm{m}^{-3}$ of sodium, and $\left[\mathrm{Cl}_{\mathrm{o}}\right] \mathrm{mole}^{-3}$ 
of chloride, at $\mathrm{pH}_{\mathrm{o}}$. At $\mathrm{t}=0$, it is assumed that the flux of every ion across the plasmalemma and the cell walls is zero and the equilibrium between the walls and the bathing medium has been established. In this situation, the concentration of ions in the water free space (WFS) of the walls is the same as in the bathing medium. Therefore the initial concentration of the ions of interest in the WFS can be expressed as $\left[\mathrm{K}_{\mathrm{o}}\right](0)$, $\left[\mathrm{Ca}_{\mathrm{o}}\right](0),\left[\mathrm{Na}_{\mathrm{o}}\right](0)$, and $\left[\mathrm{Cl}_{\mathrm{o}}\right](0)$, and $\left[\mathrm{H}_{\mathrm{o}}\right](0)$. When the concentration of ionisable sites in the Donnan free space (DFS) of the wall $\left[\mathrm{A}_{\text {sites }}\right]$, the $\mathrm{pK}$ of the wall weak acids (assumed to be single), and the intrinsic linear charge density parameter of the walls $\xi^{*}$ are given, using the WADM model analysis, the concetration of all ions in the DFS can be estimated based on their concentration in the $\mathrm{WFS}^{8)}$. These concentration are then considered as the initial concentration of the ions in the DFS and they can be expressed as $\left[\mathrm{K}_{\mathrm{w}}\right](0),\left[\mathrm{Ca}_{\mathrm{w}}\right](0),\left[\mathrm{Na}_{\mathrm{w}}\right](0)$, and $\left[\mathrm{Cl}_{\mathrm{w}}\right](0)$, and $\left[\mathrm{H}_{\mathrm{w}}\right](0)$. The WADM model analysis also provides other quantities such as the activity of each ion $(\gamma)$, the ionic strength (I), the linear charge density parameter $(\xi)$, the concentration of condensed calcium in the wall weak acids ([Ca $\left.\mathrm{Ca}_{\text {cond }}\right]$ ) since calcium is the highest valency cation available in the walls, the concentration of dissociated ionisable sites in the DFS $\left(\left[\mathrm{A}_{\mathrm{diss}}\right]\right)$, the concentration of the fixed negative charges available for the Donnan equilibrium $\left(\left[A_{\text {Donn }}\right]\right)$, the Donnan partition coeficient $(\sigma)$, and the Donnan potential of the DFS in respect to the WFS $\left(\mathrm{E}_{\mathrm{wo}}\right)$.

\subsection{Effects of Proton Efflux}

At time $0<t<t_{m}$ where $t_{m}$ is the length of the time under consideration, it is supposed that there is a proton efflux from the cell to the cell walls and the bathing medium that varies with time $\left(\mathrm{J}_{\mathrm{H}}{ }^{\text {cell }}(\mathrm{t})\right.$ in mole $\left.\mathrm{m}^{-2} \mathrm{~s}^{-1}\right)$. Based on the neutrality principles for the ion transport, it is assumed that the proton efflux is balanced by the efflux of anion $\mathrm{N}^{-}$of valence -1 wih the same magnitude $\left(\mathrm{J}_{\mathrm{N}}{ }^{\text {cell }}(\mathrm{t})=\mathrm{J}_{\mathrm{H}}{ }^{\text {cell }}(\mathrm{t})\right)$. The flux of other ions during this time are assumed to be zero.

When proton are extruded to the walls and the bathing medium, some of the extruded protons function to increase the concentration of protons in the $\operatorname{DFS}\left(\Delta\left[\mathrm{H}_{\mathrm{w}}\right]\right)$ and in the WFS $\left(\Delta\left[\mathrm{H}_{\mathrm{o}}\right]\right)$ so that the $\mathrm{pH}$ of the DFS and the WFS decreases. Some of the extruded protons also protonate the wall weak acids so that the concentration of the dissociated ionisable sites decreases $\left(\Delta\left[\mathrm{A}_{\text {diss }}\right]\right)$, and release some of the condensed calcium so that the concentration of the condensed calcium decreases $\left(\Delta\left[\mathrm{Ca}_{\text {cond }}\right]\right)$. The rest of the extruded diffuse to the external medium $\left(\Delta \mathrm{T}_{\mathrm{H}}{ }^{\text {ext }}\right.$ in mole $\left.\mathrm{m}^{-3}\right)$. In this analysis, all of these quantities are calculated at every small and equal time interval during the time under consideration $\left(\Delta t=t_{m} / n\right.$ where $n$ is the number of interval).

At time $\mathrm{t}=\mathrm{i} \Delta \mathrm{t}$ where $\mathrm{i}=1$ to $\mathrm{n}$, the change of the ionic composition of the walls from their initial ionic composition is due to all ion fluxes from $\mathrm{t}=0$ to $\mathrm{t}=\mathrm{i} \Delta \mathrm{t}$.
Therefore the calculation is started from the initial ionic composition of the walls, and then the effect of the $\mathrm{k}^{\text {th }}$ ion fluxes, where $\mathrm{k}=1$ to $\mathrm{i}$, on the ionic composition of the walls is analyzed one by one.

\subsection{Protons}

The amount of extruded protons from the cell due to proton efflux $\mathrm{J}_{\mathrm{H}}{ }^{\text {cell }}(\mathrm{k})$ during $\Delta \mathrm{t}$ in mole $\mathrm{m}^{-2}$ is

$$
\Delta T_{H}^{c e l l}(k)=J_{H}^{\text {cell }}(k) \Delta t
$$

In this case the thickness of the walls is $h$ in $m$ and it is assumed that the proportion of the DFS in the walls is $\lambda$ and the rest $(1-\lambda)$ is the WFS. Therefore,

$$
\begin{aligned}
& \Delta T_{H}^{\text {cell }}(k)=\Delta\left[A_{\text {diss }}\right](k) \lambda h+\left\{\Delta\left[H_{w}\right](k) \lambda h\right. \\
& \left.\quad+\Delta\left[H_{0}\right](k)(1-\lambda) h\right\}+\Delta T_{H}^{e x t}(k)
\end{aligned}
$$

To approach the mechanism of the fluxes, it is assumed that all amounts of the extruded ions during the time interval first fill the walls, and then it is followed by the diffusion of ions to the bathing medium. By applying the HendersonHasselbalch equation and the Donnan theory, Equation 2 becomes

$$
\begin{aligned}
& \Delta T_{H}^{\text {cell }}(k)=\Delta\left[A_{\text {diss }}\right](k) \lambda h+\left(\Delta\left[H_{w}\right](k) \lambda h\right. \\
& \left.\quad+\Delta\left[H_{0}\right](k)(1-\lambda) h\right)\left(\frac{\lambda h}{\lambda h-r H((i-k+1 \Delta t)}\right)
\end{aligned}
$$

where

$$
\begin{gathered}
\Delta\left[A_{\text {diss }}\right](k)=\left(\frac{\left[A_{\text {sites }}\right]}{\left.\gamma_{1 w}(k-1)\left[H_{w}\right] k-1\right) 10^{(p K-3)}+1}\right) \\
\left.-\frac{\left[A_{\text {sites }}\right]}{\gamma_{1 w}(k)\left[H_{w}\right](k) 10^{(p K-3)}+1}\right) \\
\Delta\left[H_{w}\right](k)=\left[H_{w}\right](k)-\left[H_{w}\right](k-1) \\
\Delta\left[H_{0}\right](k)=\frac{\gamma_{1 w}(k)\left[H_{w}\right](k)}{\sigma(k) \gamma_{10}(k)}-\left[H_{0}\right](k-1) \\
r_{H}((i-k+1) \Delta t)=\lambda h \operatorname{erfc}\left(\frac{\lambda h}{\sqrt{D_{H}(i-k+1) \Delta t}}\right) \\
-\sqrt{\frac{D_{H}(i-k+1) \Delta t}{\pi}\left(\frac{(\lambda h)^{2}}{\left.1-\left(\frac{(i-k+1) \Delta t}{D_{H}}\right)\right)}\right)}
\end{gathered}
$$

In the DFS, the activity coefficient of ions with valence $\mathrm{z}$ is defined as (Richter and Dainty, 1990b; Ryan et al., 1992),

$$
\ln \left(\gamma_{|z| w}(k)\right)=-z^{2}\left(\frac{\xi^{e f f}(k)\left[A_{\text {Donn }}\right](k)}{4 I_{w}(k)}\right)
$$

where the effective linear charge density parameter is

$$
\xi^{\text {eff }}(k)=\frac{\left[A_{\text {Donn }}\right](k)}{\left[A_{\text {sites }}\right]} \xi^{*}
$$

and the ionic strength in the DFS is 


$$
I_{w}(k)=0.5 \Sigma_{a u N} z_{N}^{2}\left[N_{w}\right](k)
$$

In the WFS, the activity coefficient of ions with valence $\mathrm{z}$ is determined using the Debye-Hückel expression,

$$
\log \left(\gamma_{|z| 0}(k)\right)=-0.509 z^{2}\left(\frac{\sqrt{I_{0}(k)}}{1+\sqrt{I_{0}(k)}}\right)
$$

where the ionic strength in the WFS is

$$
I_{0}(k)=0.5 \Sigma_{a U N} z_{N}^{2}\left[N_{0}\right](k)
$$

When Equations 1, 4, 5, 6, and 7 are substituted into Equation 3, a quadratic equation for the proton concentration in the DFS $\left(\left[\mathrm{H}_{\mathrm{w}}\right](\mathrm{k})\right)$ is obtained. To solve this equation to obtain the proton concentration in the DFS $\left(\left[\mathrm{H}_{\mathrm{w}}\right](\mathrm{k})\right)$, the values of the activity coefficient of monovalent ions in the DFS and in the WFS $\left(\gamma_{1 \mathrm{w}}(\mathrm{k})\right.$ and $\left.\gamma_{10}(\mathrm{k})\right)$ and the related Donnan partition coefficient $(\sigma(\mathrm{k}))$ are required. In this case, the previous values of these quantities $\left(\gamma_{1 \mathrm{w}}(\mathrm{k}-1)\right.$ and $\left.\gamma_{10}(\mathrm{k}-1), \sigma(\mathrm{k}-1)\right)$ are used for the starting values. After the proton concentration in the DFS $\left(\left[\mathrm{H}_{\mathrm{w}}\right](\mathrm{k})\right)$ is obtained, the proton concentration in the WFS $\left(\left[\mathrm{H}_{\mathrm{o}}\right](\mathrm{k})\right)$ is determined using the Donnan relation. Furthermore, the increase of the proton concentration in the DFS $\left(\Delta\left[\mathrm{H}_{\mathrm{w}}\right](\mathrm{k})\right)$ and in WFS $\left(\Delta\left[\mathrm{H}_{\mathrm{o}}\right](\mathrm{k})\right)$ can be determined, and the concentration reduction of the dissociated ionisable sites due to the proton efflux during $\Delta \mathrm{t}\left(\Delta\left[\mathrm{A}_{\text {diss }}\right](\mathrm{k})\right)$ can be obtained using Equation 3.

\subsection{Condensation}

The total concentration reduction of the dissociated ionisable sites is obtained from its previous values based on the following equation,

$$
A\left[A_{\text {diss }}^{T}\right](k)=\Delta\left[A_{\text {diss }}^{T}\right](k-1)+\Delta\left[A_{\text {diss }}\right](k) .
$$

Therefore the concentration of the dissociated ionisable sites can be determined from its initial concentration using

$$
\left[A_{\text {diss }}\right](k)=\left[A_{\text {diss }}\right](0)-\Delta\left[A_{\text {diss }}^{T}\right](k) \text {. }
$$

The linear charge density parameter then can be determined using

$$
\xi(k)=\frac{\left[A_{\text {diss }}\right](k)}{\left[A_{\text {sitess }}\right]} \xi * .
$$

The total concentration reduction of the condensed calcium is obtained from

$$
\Delta\left[C a_{\text {cond }}^{T}\right](k)=\frac{1}{2} \Delta\left[A_{\text {diss }}^{T}\right](k) .
$$

The concentration reduction of the condensed calcium due to $\mathrm{J}_{\mathrm{H}}{ }^{\text {cell }}(\mathrm{k})$ during $\Delta \mathrm{t}$ is obtained using

$$
\begin{gathered}
\Delta\left[C a_{\text {cond }}\right](k)=\Delta\left[C a_{\text {cond }}^{T}\right](k) \\
-\Delta\left[C a_{\text {cond }}^{T}\right](k-1) .
\end{gathered}
$$

The concentration of the condensed calcium can be determined from its previous value using the following equation.

$$
\left[C a_{\text {cond }}\right](k)=\left[C a_{\text {cond }}\right](k-1)-\Delta\left[C a_{\text {cond }}\right](k)
$$

The concentration of the fixed anions in the DFS of the walls usable for the Donnan equilibrium is determined by subtracting the concentration of the dissociated ionisable sites with the concentration of the sites occupied by the condensed calcium.

$$
\begin{aligned}
& {\left[A_{\text {Donn }}\right](k)=\left[A_{\text {diss }}\right](k)} \\
& \quad-2\left(\left[C a_{\text {cond }}\right](0)-\Delta\left[C a_{\text {cond }}^{T}\right](k)\right)
\end{aligned}
$$

\subsection{Calcium}

The calcium from the cells and the calcium released from the walls due to $\mathrm{J}_{\mathrm{H}}{ }^{\text {cell }}(\mathrm{k})$ during $\Delta \mathrm{t}$ are the source of calcium entering the DFS, the WFS and the bathing medium. Therefore, similar with equations for protons, for calcium at $\mathrm{t}=\mathrm{i} \Delta \mathrm{t}$, it is obtained

$$
\begin{aligned}
& \Delta T_{C a}^{c e l l}(k)=J_{C a}^{\text {cell }}(k) \Delta t \\
& \Delta T_{C a}^{\text {cell }}(k)+\Delta\left[C a_{\text {cond }}\right](k) \lambda h=\left(\Delta\left[C a_{w}\right](k) \lambda h\right. \\
& \left.\quad+\Delta\left[C a_{0}\right](k)(1-\lambda) h\right)\left(\frac{\lambda h}{\lambda h-r_{C a}((i-k+1) \Delta t)}\right)
\end{aligned}
$$

where

$$
\begin{aligned}
& \Delta\left[C a_{w}\right](k)=\left[C a_{w}\right](k)-\left[C a_{w}\right](k-1) \\
& \Delta\left[C a_{0}\right](k)=\frac{\gamma_{2 w}(k)\left[C a_{w}\right](k)}{\sigma^{2}(k) \gamma_{20}(k)}-\left[C a_{0}\right](k-1) \\
& r_{C a}((i-k+1) \Delta t)=\lambda h \operatorname{erfc}\left(\frac{\lambda h}{\sqrt{D_{C a}(i-k+1) \Delta t}}\right) \\
& -\sqrt{\frac{D_{C a}(i-k+1) \Delta t}{\pi}}\left(1-e^{\left.-\left(\frac{(\lambda h)^{2}}{D_{C a}(i-k+1) \Delta t}\right)\right)}\right)
\end{aligned}
$$

Using the previous values of the activity coefficient of divalent ions in the DFS and in the WFS $\left(\gamma_{2 \mathrm{w}}(\mathrm{k}-1)\right.$ and $\left.\gamma_{2 \mathrm{o}}(\mathrm{k}-1)\right)$ for the starting values of the activity coefficient of divalent ions in the DFS and in the WFS $\left(\gamma_{2 \mathrm{w}}(\mathrm{k} 1)\right.$ and $\left.\gamma_{20}(\mathrm{k} 1)\right)$, as for protons, the equation obtained from the substitution of Equations 17, 20, 22, 23, and 24 into Equation 21, is solved to determine the calcium concentration in the DFS $\left(\left[\mathrm{Ca}_{\mathrm{w}}\right](\mathrm{k})\right)$. After that, the calcium concentration in the WFS $\left(\left[\mathrm{Ca}_{\mathrm{o}}\right](\mathrm{k})\right)$ is determined using the Donnan relation. Furthermore, the increase of the calcium concentration in the DFS $\left(\Delta\left[\mathrm{Ca}_{\mathrm{w}}\right](\mathrm{k})\right)$ and in the WFS $\left(\Delta\left[\mathrm{Ca}_{\mathrm{o}}\right](\mathrm{k})\right)$ can be determined.

\subsection{Other monovalent ions}

For potassium, sodium, chloride ions and the negative ion transported to balance the transport of protons, the similar method is employed to obtain their concentration in the DFS and in the WFS, and finally the increase of their concentration in the DFS and in the WFS. 


\subsection{Donnan Considerations} Therefore,

In the DFS, electric neutrality must be satisfied.

$$
\begin{aligned}
& {\left[A_{\text {Donn }}\right](k)+\left[N_{w}^{-}\right](k)+\left[C l_{w}\right](k)} \\
& =\left[H_{w}\right](k)+\left[K_{w}\right](k) \\
& \quad+\left[N a_{w}\right](k)+2\left[C a_{w}\right](k)
\end{aligned}
$$

The concentration of each ion in the DFS can be expressed in term of the increase of the ion concentration and the previous ion concentration in the DFS and in the WFS, that is:

$$
\begin{aligned}
& {\left[N_{w}\right](k)=\frac{(\sigma(k))^{2} \gamma_{|z| 0}(k)}{\gamma_{|z| w}(k)+(\sigma(k))^{2}}\left(\Delta\left[N_{w}\right](k)\right.} \\
& \left.+\Delta\left[N_{0}\right](k)+\left[N_{w}\right](k-1)+\left[N_{0}\right](k-1)\right)
\end{aligned}
$$

Here, $\mathrm{N}$ is either proton, calcium, potassium, sodium, chloride or $\mathrm{N}^{-}$ion and $\mathrm{z}$ is the valence of the ions. When Equation 26 is applied on all of these ions and the results are substituted into Equation 25, a polynomial of degree 4 to solve for the Donnan partition coefficient $(\sigma(\mathrm{k}))$ is obtained. Using a standard routine, the roots of the polynomial can be found and the positive root of the polynomial is selected for $\sigma(\mathrm{k})$. This value is then used to determine all other parameters in the DFS and in the WFS. This calculation is carried out iteratively until the values of all parameters approach a steady state. At this state, the iteration to obtain the ionic composition of the walls for $\mathrm{k}^{\text {th }}$ ion fluxes at $\mathrm{t}=\mathrm{i} \Delta \mathrm{t}$, where $\mathrm{k}=1$ to $\mathrm{i}$, has been completed.

After $\mathrm{k}=\mathrm{i}$, the Donnan potential, the potential of the DFS in respect to the WFS, at this state is determined using

$$
E_{w o}(i)=-\frac{R T}{F} \ln (\sigma(k=i)) .
$$

$\mathrm{R}, \mathrm{T}$ and $\mathrm{F}$ have their usual definitions.

The flux of ions from the walls to the bathing medium at $\mathrm{t}=\mathrm{i} \Delta \mathrm{t}$ is defined as the difference between the total amount of the ions that diffuse from the walls to the external medium at $\mathrm{t}=(\mathrm{i}-1) \Delta \mathrm{t}$ and at $\mathrm{t}=\mathrm{i} \Delta \mathrm{t}$ divided by the time difference,

$$
J_{N}^{e x t}(i)=\frac{T_{N}^{e x t}(i)-T_{N}^{e x t}(i-1)}{\Delta t}
$$

where,

$$
\begin{aligned}
& T_{N}^{e x t}(i)=\sum_{k=1}^{i}\left(\Delta\left[N_{w}\right](k)+\Delta\left[N_{0}\right](k)\right) \\
& \frac{r N((i-k+1) \Delta t)}{a-r N((i-k+1) \Delta t)}
\end{aligned}
$$

$\mathrm{N}$ is either proton, calcium, potassium, sodium, chloride or $\mathrm{N}^{-}$ion. $\mathrm{r}$ is according to Equation 7 or 24 for cations, however $\lambda \mathrm{h}$ is substituted with $(\lambda-1) \mathrm{h}$ for anion. In the equation for $\mathrm{r}, \mathrm{D}$ is the diffusion coefficient of the DFS for cations, however for anions it is the diffusion coefficient of the WFS.

\section{Simulation Process}

For the analysis of the effect of proton fluxes to the ionic composition in the walls, it is considered a plant tissue which has 10 cells in its thickness. It is necessary to mention the number of cells in tissue thickness since it is supposed that the calculation model will be used to estimate the fluxes of ions outside the plant tissue surface during proton extrusion from all of the cells to their walls. Therefore, it needs to encounter all wall thickness in the direction of the fluxes. When the calculation model is used to estimate the fluxes of ions outside a single plant cell, the calculation process is similar. The concentration of the ionisable sites of the cells walls $\left(\left[\mathrm{A}_{\text {sites }}\right]\right)$ is 800 moles $\mathrm{m}^{-3}$ as reported and used for Chara in the work of Dainty ${ }^{8,10)}$. The pK of the wall weak acids is 3.0 and the intrinsic linear charge density parameter $\left(\xi^{*}\right)$ is 0.71 as found in Sphagnum russowii ${ }^{6}$. The wall thickness of each cell $(\lambda)$ is $1.0 \mu \mathrm{m}$ and the portion of the DFS in the walls is 0.5 as reported for Chara ${ }^{11)}$. The diffusion coefficient of ions in the WFS is assumed to be the same as in open water, that are $9.17 \times 10^{-9} \mathrm{~m}^{2} \mathrm{~s}^{-1}$ for protons, $1.99 \times 10^{-9} \mathrm{~m}^{2} \mathrm{~s}^{-1}$ for calcium, $1.9 \times 10^{-9} \mathrm{~m}^{2} \mathrm{~s}^{-1}$ for potassium, $1.28 \times 10^{-9} \mathrm{~m}^{2}$ $\mathrm{s}^{-1}$ for sodium, and $1.93 \times 10^{-9} \mathrm{~m}^{2} \mathrm{~s}^{-1}$ for chloride. The diffusion coefficient of ions in the DFS is assumed to be $1 / 5$ of that in open water. The bathing medium contains 0.1 mole $\mathrm{m}^{-3}$ potassium, 0.1 mole $\mathrm{m}^{-3}$ calcium, 0.02 mole $\mathrm{m}^{-3}$ sodium, and 0.3 mole $\mathrm{m}^{-3}$ chloride at $\mathrm{pH} 6$.

It is assumed that there is proton efflux at the plasmalemma described by the following equation in nmol. $\mathrm{m}^{-2} \mathrm{~s}^{-1}$ (influx positive).

$$
J_{H}^{\text {cell }}(t)=-300\left(1-e^{-t / S}\right)
$$

This assumption is made since in general the response of plant cells to a certain treatment usually is exponentially and asymptotically increase to a certain value. To satisfy electric neutrality principle, the proton efflux is balanced by the efflux of $\mathrm{N}^{-}$. The fluxes of calcium, potassium, sodium and chloride at the plasmalemma are assumed to be zero.

\section{Results}

When the calculation model of the effect of proton fluxes to the ionic composition in the walls using WADM model is applied, it is found that due to the asymptotically increased proton efflux at the plasmalemma, the estimated proton and calcium effluxes from the walls to the external medium also increase (Figure 1). This describes that there is calcium release from the condensed phase in the walls by some of the extruded protons. In the beginning, the increase of calcium efflux is faster than the proton efflux. After the proton efflux at the plasmalemma levels off, the estimated calcium efflux starts to decrease. 


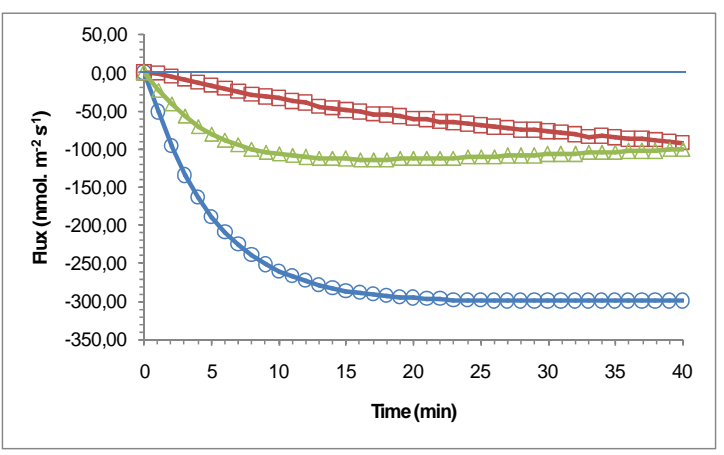

Figure 1. The proton efflux at the plasmalemma (o), and the proton $(\square)$ and calcium $(\Delta)$ effluxes outside the walls estimated using the WADM model for fluxes. The wall parameters are described as in the Experiments.

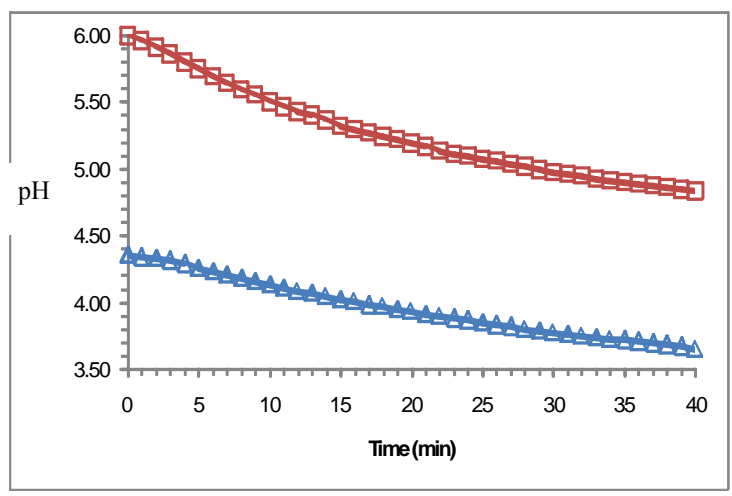

Figure 2. The $\mathrm{pH}$ of the DFS $(\Delta)$ and the WFS ( $\square$ ) estimated using the WADM model for fluxes during the proton efflux at the plasmalemma used in Figure 1.

During the proton efflux at the plasmalemma, the $\mathrm{pH}$ of the DFS also decreases from about 4.4 to 3.7 and the $\mathrm{pH}$ of the WFS decreases from 6.0 to about 4.9 (Figure 2). This describes that during proton efflux, the acidification of the walls also happens.

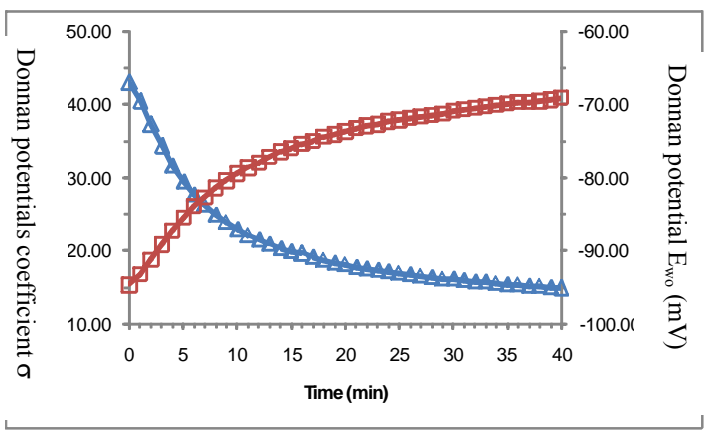

Figure 3. The Donnan partition coefficient $\sigma(\Delta)$ and the Donnan potential $\mathrm{E}_{\mathrm{wo}}(\square)$ estimated using the WADM model for fluxes during the proton efflux at the plasmalemma used in Figure 1.
For the representatives of wall parameters that change during the proton efflux at the plasmalemma, the Donnan partition coefficient and the Donnan potential during the proton extrusion is shown in Figure 3. The Donnan partition coefficient decreases from about 43 to about 15 . Meanwhile the Donnan potential depolarizes from about $-95 \mathrm{mV}$ to about -69 $\mathrm{mV}$. The change of these two parameters indicates that the ionic composition in the walls during the proton efflux at the plasmalemma is continuously altered.

\section{Discussion}

According to the WADM model ${ }^{4-8)}$, when the $\mathrm{pH}$ of the DFS is decreased to approach the $\mathrm{pK}$ of the wall weak acids, the same $\mathrm{pH}$ decrease causes more calcium release. Therefore the decrease of the estimated calcium efflux, when the proton efflux at the plasmalemma levels off, indicates that a constant proton efflux at the plasmalemma does not decrease the $\mathrm{pH}$ of the DFS linearly. In this case the rate of the decrease becomes smaller. This is shown in Figure 2.

In Figure 1, calcium efflux from the walls does not drop to zero during this time. This indicates that some condensed calcium in the walls is still available after 40 minutes. In this condition, the concentration of the dissociated ionisable sites useable for the Donnan equilibrium has not been altered. Meanwhile, some of the extruded protons, the extruded $\mathrm{N}^{-}$ions and the released calcium increase the ionic strength of the DFS and the WFS in the walls. Therefore the Donnan partition coefficient decreases and the Donnan potential becomes more positive (Figure 3). For potassium, sodium and chloride that do not have any source in the walls, the decrease of the Donnan partition coefficient relates to the decrease of the ion concentration in the DFS and the increase of the ion concentration in the WFS. In this case, the decrease of the ion quantity in the DFS is the same as the increase of the ion quantity in the WFS. Therefore there are no fluxes of those ions from the walls to the bathing medium.

In the absence of calcium flux in at the plasmalemma, the source of calcium entering the DFS, the WFS and the bathing medium is the calcium released from the condensed phase of the walls during proton extrusion. However, if Manning condensation is not considered in this model of the walls so that condensed calcium in the walls does not exist, there would be not calcium release during proton extrusion. In this case, as with other ions that do not have any sources in the walls, changes of Donnan equilibrium during proton extrusion only cause exchange of calcium between the DFS and the WFS within the walls. Therefore, there would be not calcium efflux from the walls to the bathing medium. Manning condensation must be included in the model of walls in order to allow calcium efflux from the walls to the bathing medium during proton extrusion.

When the concentration of ionisable sites is increased, the patterns of the estimated proton and 
calcium effluxes from the walls to the bathing medium are the same. The higher concentration of the ionisable sites causes bigger calcium efflux and smaller proton efflux. The effect is not linear as expected from the Henderson-Hasselbalch equation.

When the $\mathrm{pK}$ of the wall weak acids is altered, the position of the working $\mathrm{pH}$ of the DFS relative to the $\mathrm{pK}$ is also changed. Therefore, when the $\mathrm{pK}$ is increased so that it becomes closer to the working $\mathrm{pH}$, the same $\mathrm{pH}$ decrease due to proton extrusion causes a larger calcium release. As the results, the estimated calcium efflux from the walls to the bathing medium is bigger and the estimated proton efflux is smaller. When the $\mathrm{pK}$ is increased further, the available initial condensed calcium in the walls is less. If this condition happens, after some time the extruded protons may release all of the condensed calcium so the calcium efflux becomes absent. In this case, the proton extrusion only causes an exchange of calcium between the DFS and the WFS.

When the intrinsic linear charge density parameter $\xi^{*}$ is altered, it does not affect the estimated proton and calcium effluxes from the walls to the bathing medium as long as the linear charge density parameter $\xi$ still does not drop below 0.5 during proton extrusion. When $\xi$ drops below 0.5 , there is not any condensed calcium in the walls to be released and the calcium efflux becomes absent. When $\xi^{*} \leq 0.5$, the initial concentration of condensed calcium in the walls is zero and the wall can be considered as a classic Donnan system only.

To examine the WADM model for fluxes, it is necessary to have the observed data of simultaneous flux measurement of related ions, which are proton and calcium, close to the tissue surface. The observed proton and calcium fluxes must of course be related to a certain treatment that is expected to cause proton extrusion from inside the cell to the cell walls. The simultaneous flux observation may be carried out using ion selective microelectrode ${ }^{12-13)}$. In this case, as the input of the WADM model for fluxes, the proton efflux is first generated from the observed proton and calcium fluxes using their total transported electric charges. Using the generated proton efflux as the input, the WADM model for fluxes is then used to regenerate the proton and calcium fluxes outside the cell walls. Arif and Newman have used this model for the observed proton and calcium fluxes during fusicoccin action on oat coleoptiles ${ }^{9}$. The result showed that the calculated proton and calcium fluxes are matched well to the observed data. Therefore, this WADM model for fluxes is successful to describe the proton-calcium exchange during proton extrusion induced by fusicoccin action in oat coleoptiles ${ }^{9)}$. On pea epicotyl segments ${ }^{14)}, 10^{-2} \mathrm{~mol} \mathrm{~m}^{-3}$ fusicoccin (FC) is also observed to cause proton and calcium effluxes outside the cell walls. The aplication of the WADM model for fluxes on these data also shows that the calculated data as the output of the WADM model for fluxes are matched with the observed proton and calcium effluxes. This indicates that the WADM model for fluxes is adequate to describe the exchange of wall calcium with the proton extruded from the cell during proton extrusion.

Exchange of wall calcium by extruded protons from the cells must be considered in studying proton efflux as the results of some treatments. Wall calcium involves in determining the structural rigidity of the cell walls so that the calcium release from the wall will contribute to the growth of plant cells ${ }^{15}$ ). This analysis is also in agreement to the reports that the increase of the external salinity will decrease the extracellular water space $\mathrm{pH}$ as the result of the exchange between sodium ions from the external solution with protons of carboxyl groups of the cell walls of Spinacia oleracea L. roots ${ }^{16)}$. It is also shown that cell wall acidic properties are enhanced for all types of cation exchangeable groups by increasing salinity concentration of the external solution in halophyte plant roots ${ }^{17)}$. The resulting calcium release from the walls may also increase its chemical potential gradient between the cell walls to the cytoplast so that any calcium channel opening in such situation may produce communication signal for cellular responses ${ }^{13,18)}$. Calcium is known to have a role in signaling system of plant ${ }^{19-21)}$. These reports suggest that the calcium release from cell walls by extruded protons may contribute to the signaling process.

\section{Conclusion}

The WADM model for fluxes provides a quantitative analysis to estimate wall quantities such as wall ionic composition and the ion fluxes from the walls to the bathing medium during proton extrusion at the plasmalemma. It shows that the proton extrusion causes effluxes of both proton and calcium from the walls. This calcium-proton exchange during proton extrusion from plant cell walls must be considered when ion fluxes are observed outside plant cell walls such as in the measurement of fluxes using ion selective microelectrodes. The WADM model for fluxes is successful to describe the proton-calcium exchange in the walls expected during proton extrusion. Besides the ion composition of the bathing medium, the results of the WADM model for fluxes also depend on the wall parameter such as the ionisable site concentration and the $\mathrm{pK}$ of the wall weak acid.

\section{References}

1. N. R. Meychik and I.P. Yermakov, Ion exchange properties of plant root cell walls, Plant and Soil, 234, 181, 2001.

2. H. Sentenac, and C. Grignon, A model for predicting ionic equilibrium concentrations in cell walls, Plant Physiol., 68, 415, 1981

3. G. S. Manning, Limiting laws and counterion condensation in polyelectrolyte solution. I. Colligative properties, J. Chem. Phys., 51, 924, 1969. 
4. C. Richter and J. Dainty, 1989a, Ion behavior in plant cell walls. I. Characterization of the Sphagnum russowii cell wall ion exchanger, Can. J. Bot., 67, 451, 1989a.

5. C. Richter and J. Dainty, Ion behavior in plant cell walls. II. Measurement of Donnan free space, anion-exclusion space, anion-exchange capacity, and cation-exchange capacity in delignified Sphagnum russowii cell walls, Can. J. Bot., 67, 460, $1989 \mathrm{~b}$.

6. C. Richter and J. Dainty, Ion behavior in plant cell walls. III. Measurement of the mean charge separation distance and the linear charge density parameter in delignified Sphagnum russowii cell walls, Can. J. Bot., 68, 768, 1990a.

7. C. Richter and J. Dainty, Ion behavior in plant cell walls. IV. Selective cation binding by Sphagnum russowii cell walls, Can. J. Bot., 68, 773, $1990 \mathrm{~b}$.

8. P. R. Ryan, I.A. Newman and I. Arif, Rapid calcium exchange for protons and potassium in cell walls of Chara, Plant Cell Environ., 15, 675, 1992.

9. I. Arif and I.A. Newman, Proton efflux from oat coleoptile cells and exchange with wall calcium after IAA or fusicoccin treatment, Planta, 189, 377, 1993.

10. J. Dainty, A.B. Hope and C. Denby, Ionic relations of cells of Chara Australis. II. The indifussible anions of the cell wall, Aus. J. Biol. Sci., 13, 267, 1960.

11. Dainty, J. and A.B. Hope, Ionic relations of cells of Chara Australis. I. Ion exchange in the cell wall, Aus. J. Biol. Sci., 12, 395, 1959.

12. I. A. Newman et al., Fluxes of $\mathrm{H}^{+}$and $\mathrm{K}^{+}$in corn roots. Characterization and stoichiometries using ion selective microelectrodes, Plant Physiol., 84, 1177, 1987.

13. I. A. Newman, Ion transport in roots: measurement of fluxes using ion-selective microelectrodes to characterize transporter function, Plant Cell Environ., 24, 1, 2001.

14. I. Arif, Calcium Release from Cell Walls of Pea Epicotyls Caused by Proton Extrusion during Fusicoccin Action, Jurnal Matematika dan Sains, 16, 53, 2011.

15. P.K. Hepler, Calcium: a central regulator of plant growth and development, The Plant Cell, 17, 2142, 2005.

16. Meychik, N.R., J.I. Nikolaeva and I.P. Yermakov, 2006, Ion exchange properties of cell walls of Spinacia oleracea L. roots under different environmental salt conditions, Biochemistry (Mosc), 71(7), 781-789.

17. N. R. Meychik, J.I. Nikolaeva and I.P. Yermakov, Ion exchange properties of the root cell walls isolated from the halophyte plants (Suaeda altissima L.) grown under conditions of different salinity, Plant and Soil, 277, 163, 2005.

18. P. K. Hepler and L.J. Winship, Calcium at the cell wall-cytoplast interface, Journal of Integrative Plant Biology, 52, 147, 2010.

19. S. W. Medvedev, Calcium signaling system in plants, Russian Journal of Plant Physiology, 52, 249, 2010.

20. M. R. McAinsh and J.K. Pittman, Shaping the calcium signature, New Phytologist, 181, 275, 2009.

21. A. N. Dodd, J. Kudla and D. Sanders, The language of calcium signaling, Annu. Rev. Plant Biol., 61, 593, 2010. 